\title{
A editora portuguesa Livros do Brasil e suas obras eróticas na ditadura militar brasileira
}

\author{
The Portuguese publisher Livros do Brasil and its erotic works \\ during the Brazilian military dictatorship
}

\section{Sandra Reimao}

Universidade de São Paulo - USP - São Paulo - Brasil

\begin{abstract}
Resumo: Há no Arquivo Nacional cinco pareceres, datados de 1977, do Serviço de Censura de Diversões Públicas, órgão do Ministério da Justiça do Brasil, indicando o veto a cinco livros eróticos publicados pela editora portuguesa Livros do Brasil. Visando elaborar uma compreensão contextualizada destes pareceres, esse estudo aborda inicialmente a história da editora Livros do Brasil e seu perfil editorial; a seguir, busca caracterizar as edições eróticas desta editora vetadas no Brasil e, por fim, discute e analisa especificidades dos pareceres censórios brasileiros e de suas articulações argumentativas.
\end{abstract}

Palavras-chave: Editora Livros do Brasil, censura a livros, ditadura militar brasileira.

Abstract: There are five opinions in the Brazilian National Archives, dated 1977, Censorship Service, an organ of the Ministry of Justice, indicating the veto of five erotic books published by the Portuguese publisher Livros do Brasil. Aiming at elaborating a contextualized understanding of these opinions, this study addresses the history of the publisher Livros do Brasil and its editorial profile; and tries to characterize the erotic editions of this publisher that have been banned in Brazil. Finally, it discusses and analyses the specificities of Brazilian censorship opinions and their argumentative articulations.

Key-words: Portuguese publisher Livros do Brasil, Censorship, Brazilian military dictatorship. 
A minha vida secreta - autobiografia erótica, Memórias eróticas de um burguês, Aventuras de um sádico, A pérola - um jornal erótico, Jou pu tuan - o livro erótico chinês - estes são os títulos de cinco livros eróticos editados em Portugal e censurados no Brasil em 1977. O presente artigo visa a uma compreensão contextualizada destes atos censórios. O estudo está articulado em três tópicos: a editora Livros do Brasil; os livros censurados; e, por fim, uma abordagem analítica dos pareceres brasileiros indicativos de vetos censórios.

\section{Livros do Brasil - uma editora portuguesa}

A editora portuguesa Livros do Brasil foi fundada por António Augusto de Souza-Pinto, em 1944, a partir da aquisição da filial lisboeta da Editora Civilização Brasileira. António Augusto de SouzaPinto também era proprietário da Editora Livros de Portugal, com sede no Rio de Janeiro.

Vejamos esta história:

- Em 1929, a editora Civilização Brasileira é fundada por Getúlio Costa, Ribeiro Couto e Gustavo Barros.

- Em 1932, a Civilização Brasileira é adquirida por Octalles Marcondes Ferreira que a incorpora como um selo da Companhia Editora Nacional.

- Também em 1932, Octalles abre uma filial da Civilização Brasileira em Portugal.

- Em 1944, Octalles vende esta filial a seu gerente, pois havia "chegado à conclusão de que o resultado comercial não justificava $o$ esforço" (HALLEWELL, p. 401).

- Em 1944, António Augusto de Souza-Pinto compra a filial portuguesa da Companhia Editora Nacional, então de posse de seu antigo gerente, e altera o nome para Livros do Brasil.

Como assinala Nuno Medeiros (2015), "O nascimento da Livros do Brasil é literalmente transatlântico, forjado nos cruzamentos e passagens de livros, ideias e pessoas entre os dois lados do oceano onde a língua portuguesa é falada". Medeiros completa a observação afirmando que a editora Livros do Brasil

não foi a primeira a publicar títulos brasileiros em Portugal, mas as suas primeiras três décadas de atividade garantiram a ela 0 status de pioneira na promoção em Portugal (e nas colônias portuguesas, especialmente na África) da literatura e da cultura brasileiras clássica e contemporânea" (MEDEIROS, p. 90).

A promoção de trocas e intercâmbios entre literaturas que partilham a mesma língua era o anseio original do visionário Souza-Pinto (SOUZA-PINTO, pp.9-10). Como o próprio nome da editora indica, o objetivo inicial da Livros do Brasil era, pois, publicar e divulgar em Portugal a literatura brasileira:

- grande projeto de partida centrou-se na edição sistemática, dirigida ao público-leitor português, de grandes escritores brasileiros José Lins do Rego, Graciliano Ramos, Erico Verissimo, Jorge Amado, José Cândido de Carvalho, Euclides da Cunha, Cyro dos Anjos, Gilberto Freyre, João Condé, José de Alencar, Lygia Fagundes Telles, Octavio de Faria, Ribeiro Couto, Rubem Braga, João Guimarães Rosa, Herberto Sales e outros (BEJA, p. 15).

Em menos de 15 anos, a Livros do Brasil se tornou uma das grandes editoras portuguesas, publicando não só literatura brasileira, mas disseminando em Portugal a literatura estrangeira em geral (cf: MEDEIROS, p. 92).

No sítio eletrônico da editora, destaca-se que:

seu vastíssimo catálogo inclui diversos estilos e gêneros literários, distinguindo-se o trabalho de edição de obras escolhidas ou completas de autores tão significativos como André Malraux, Albert Camus, John Steinbeck, Pearl Buck e Ernest Hemingway. De destacar, também, a edição da mais antiga coleção policial publicada em Portugal, a Vampiro, com mais de 680 títulos, e da célebre coleção de obras de Eça de Queiroz (www.livrosdobrasil.pt).

António Augusto de Souza-Pinto nasceu em Portugal, cresceu em Angola e viveu um tempo no Brasil, o que permite "supor que esta vivência inicial capacitou Souza-Pinto a desenvolver uma apreciação informada da diversidade das culturas" (MEDEIROS, p. 86).

Atualmente (2015), a Livros do Brasil pertence à Editora Porto - o maior grupo editorial português. A aquisição se deu em janeiro de 2015. O jornal 
português Público noticiou a aquisição da seguinte forma:

A Porto Editora comprou a marca Livros do Brasil (...). A chancela Livros do Brasil - os seus livros, o seu catálogo de autores e as suas traduções - passam assim a integrar aquele que é atualmente o maior grupo editorial português e que engloba já as chancelas Areal, Lisboa Editores, Sextante, Assírio \& Alvim e a Bertrand e o Círculo de Leitores (que pertenceram ao grupo alemão Bertelsmann) (COUTINHO, s/p).

Em entrevista, o administrador da Porto Editora, Vasco Teixeira, destacou que os editores se sentiam "muito orgulhosos de ter no nosso catálogo o Ernest Hemingway, John Steinbeck, Anne Frank, as edições mais reputadas do Eça", pois obras e edições deste tipo "são valores a que damos importância e gostamos de preservar" (COUTINHO, s/p).

\section{Cinco livros eróticos}

Há, no Arquivo Nacional, em Brasília, no fundo/coleção da Divisão de Censura de Diversões Públicas, cinco pareceres datados de 1977 indicando vetos a cinco livros eróticos publicados pela editora portuguesa Livros do Brasil. Estes mesmos títulos aparecem também na lista de livros censurados incluída na obra Nos bastidores da censura, de Deonísio da Silva.

Os livros vetados são:

1.

Título: A minha vida secreta - autobiografia erótica

Título original: My Secret Life (vários volumes)

Autor: anônimo [inglês]

Primeira edição: composta e impressa em Amsterdã - aprox. 1890

Edição portuguesa vetada no Brasil: Editora Livros do Brasil, 2 vols., [1975]

Data do parecer de veto brasileiro: 22 novembro 1977

Argumento censório: Decreto Lei 1077, art. 1

2.

Título: Memórias eróticas de um burguês

Título original: Suburbans Souls

Autor: anônimo [inglês]
Primeira edição: Inglaterra, 1901

Edição portuguesa vetada no Brasil: Editora Livros do Brasil, [1976]

Data do parecer de veto brasileiro: 30 novembro 1977

Argumento censório: Decreto Lei 1077 e Decreto20.493/46, art.41 a, c

3.

Título: Aventuras de um sádico

Título original: $A$ Man with a Maid

Autor: anônimo [inglês]

Primeira edição: Inglaterra, final do século 19

Edição portuguesa vetada no Brasil: Editora Livros do Brasil, [1976]

Data do parecer de veto brasileiro: 22 novembro 1977

Argumento censório: Decreto Lei 1077, art. 1

4.

Título: A pérola- um jornal erótico

Título original: The Pearl

Autor: anônimo [inglês]

Primeira edição: 18 números - de julho de 1879 a dezembro de 1880

Edição portuguesa vetada no Brasil: Editora Livros do Brasil, 2 vols., [1975/76]

Data do parecer de veto brasileiro: 28 novembro 1977

Argumento censório: sem indicação de legislação

5.

Título: Jou pu tuan - o livro erótico chinês

Título original: Jou Pu Tuan

Autor: $\mathrm{Li} \mathrm{Yu}$

Primeira edição: original - China, século 17

Edição portuguesa vetada no Brasil: Editora Livros do Brasil, [1975]

Data do parecer de veto brasileiro: 21 novembro 1977

Argumento censório: Decreto-Lei 1077, art. 1 
Imagem 1: A peróla, um jornal erótico

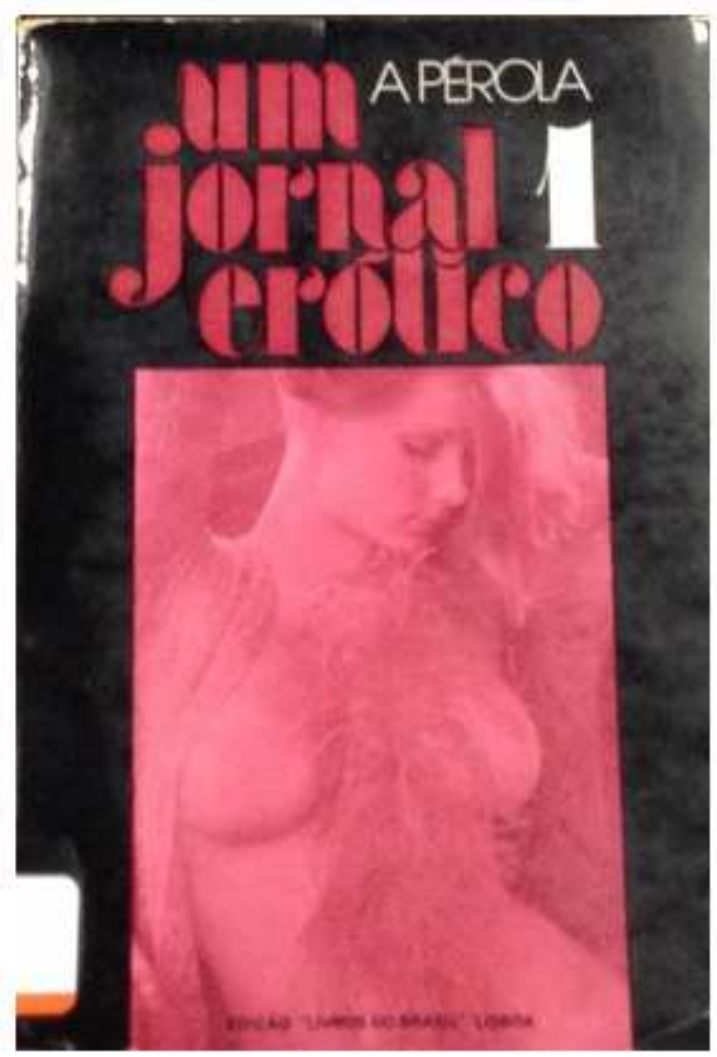

Fonte: cópia da autora

Imagem 2: O livro erótico chinês

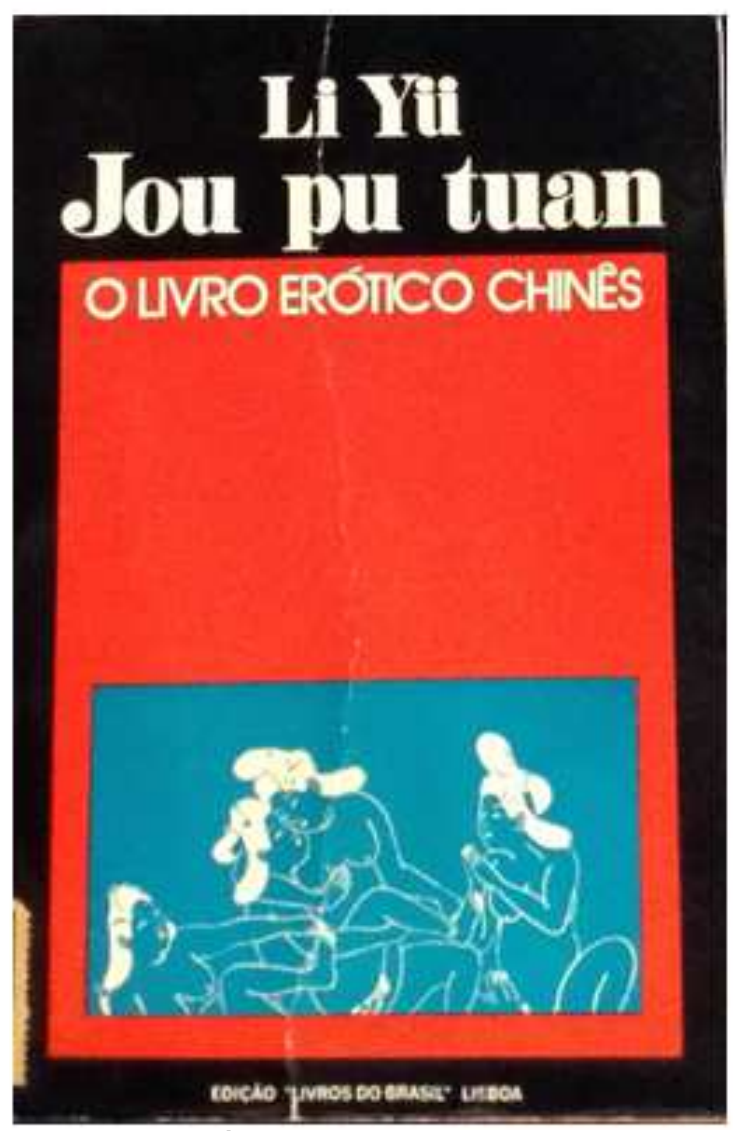

Fonte: cópia da autora
Notemos, inicialmente, que os cinco livros acima listados são clássicos mais ou menos consolidados da literatura erótica: um deles é um texto chinês do século XVII, ao passo que os outros quatro pertencem à literatura erótica da época vitoriana - denominação que abrange o período do reinado da rainha Vitória na Inglaterra, de 1837 a 1901, momento de grandes transformações políticas e sociais e também, ao menos aparentemente, de valorização de comportamentos moralistas e preconceituosos.

Apesar de nas edições portuguesas aqui enfocadas as capas serem bastante apelativas, com fotos ou desenhos de corpos nus ou seminus em posições eróticas, a escolha dos textos publicados revela certa preocupação cultural, com apresentações e prefácios bastante cuidadosos, indicando o significado sócio-histórico da obra e também informando sobre aspectos editoriais.

Assim, por exemplo, no prefácio a Jou pu tuan - o livro erótico chinês, avisa-se que a edição portuguesa se baseou na versão japonesa de 1705 e na edição chinesa de 1943; na contracapa de $A$ pérola, um jornal erótico, explica-se que a edição é "integral e conforme o texto originário, impresso de 1879 a 1880".

Sobre o valor literário e cultural das obras em pauta, lê-se, por exemplo, no prefácio de $A$ minha vida secreta, que "a história social das experiências sexuais não fazia parte da consciência social da sociedade vitoriana" e que a literatura erótica tem a função de desvendar este não dito.

Outro exemplo se encontra nas dobras da capa de Memórias eróticas de um burguês, onde se explica que as Memórias "pertencem aos domínios da sociologia e da sexologia e são, segundo o erudito investigador Legman, uma das obras fundamentais da literatura erótica européia".

Salientemos que, no prefácio do volume 1 de $A$ Pérola, um jornal erótico, há uma verdadeira avaliação sociológica da obra: " $A$ Pérola não pode ser considerada nem um modelo de literatura nem um guia pornográfico" afirma o prefaciador, acrescentando que "o seu valor é ainda o de 
contribuir para um esclarecimento franco do que foi a verdadeira mentalidade européia dos finais do século XIX". No início do prefácio, informava que $A$ Pérola, um dos primeiros magazines eróticos dos tempos modernos, "deu origem a uma verdadeira 'moda' de periodismo secreto na Europa do primeiro decênio do século XX e antecessor das grandes revistas eróticas do nosso tempo".

As cinco edições portuguesas em foco foram publicadas nos anos de 1975 e 1976, ou seja, integram o boom editorial de livros políticos e eróticos que teve início nos últimos anos da ditadura fascista de Salazar e Marcelo Caetano (1933-1974), e se expandiu depois da Revolução dos Cravos, de 25 de Abril de 1974, que restabeleceu as liberdades democráticas em Portugal (SILVA, F., pp.5-10).

\section{Sobre os pareceres censórios}

Os cinco pareceres brasileiros indicativos de veto censório para as obras acima listadas foram elaborados em datas bastante próximas, sendo que quatro deles recorrem ao mesmo argumento censório, o Decreto-Lei 1077, com destaque (em três pareceres) para o artigo 1․ Citando: Decreto-Lei 1077, Art. 1ํ - "Não serão toleradas as publicações e exteriorizações contrárias à moral e aos bons costumes quaisquer que sejam os meios de comunicação".

De maneira geral, podemos dizer que os textos dos pareceres censórios em foco apresentam quatro momentos: 1) alguma indicação do contexto do momento de elaboração da obra; 2) resumo da obra; 3) avaliação da obra - no geral moral, havendo também algumas observações literárias; 4) referência à legislação censória; 5) ressalvas e destaques ao raciocínio do parecer apresentado.

Entre as anotações que, nos pareceres, visam contextualizar a obra analisada, vemos, por exemplo, no de Memórias eróticas de um burguês, que o livro foi "escrito em fins do século passado, aborda as experiências amorosas de um homem que, sob a capa do anonimato, revela a profunda libertinagem de suas relações (...)"; já o parecer de $A$ pérola - um jornal erótico explica, em seu primeiro parágrafo, que esse jornal foi "um periódico secreto do século XIX, em números de dezoito publicações, de julho de 1879 e dezembro de 1880". Todo o parágrafo (10 linhas) é, na verdade, uma citação do prefácio do livro que é dada entre aspas.

Os resumos apresentados nos pareceres acabam por julgar moralmente as narrativas. O resumo de $A$ pérola - um jornal erótico, por exemplo, afirma que o jornal conta "em pormenores as relações sexuais da mais alta burguesia da época [, ] narra em documentários (sic) as grandes orgias", e sintetiza a lista dizendo haver no livro "todo o tipo de práticas sexuais anômalas". O parecer sobre a obra ensaia uma chave explicativa para a profusão dessas práticas: "O prazer era procurado bestialmente, sem reserva ou escrúpulos (...) [naquela] sociedade saciada e extenuada de orgasmos”. Já o parecer de Aventuras de um sádico afirma que o livro descreve "cenas sado-masoquistas revoltantes". E o parecer de Jou Pu Tuan - o livro erótico chinês, depois de copiar o resumo da contracapa do livro, "aventura de um jovem estudante, extremamente belo e inteligente, envolvido com seis mulheres (...)", afirma que a obra "visa explorar o sexo em sua forma mais deprimente".

Em alguns pareceres encontramos também julgamentos literários. No de $A$ minha vida secreta, há uma avaliação sobre a plausibilidade do enredo: "numa explosão que nos parece às vezes fantasiosa, relata suas atividades sexuais (...) enfim orgias fabulosas (...) que nos faz lembrar a famosa Sodoma". Há também julgamentos sobre a linguagem: "em linguagem de baixíssimo teor literário" (parecer de Aventuras de um sádico); "acrescentado ainda a grosseria da tradução ora apresentada" (parecer de A minha vida secreta). 
Imagem 3 - trecho do parecer relativo ao livro $A$ Pérola - um jornal erótico enfraquecer as reservas morais da família, para atingir o Estado".

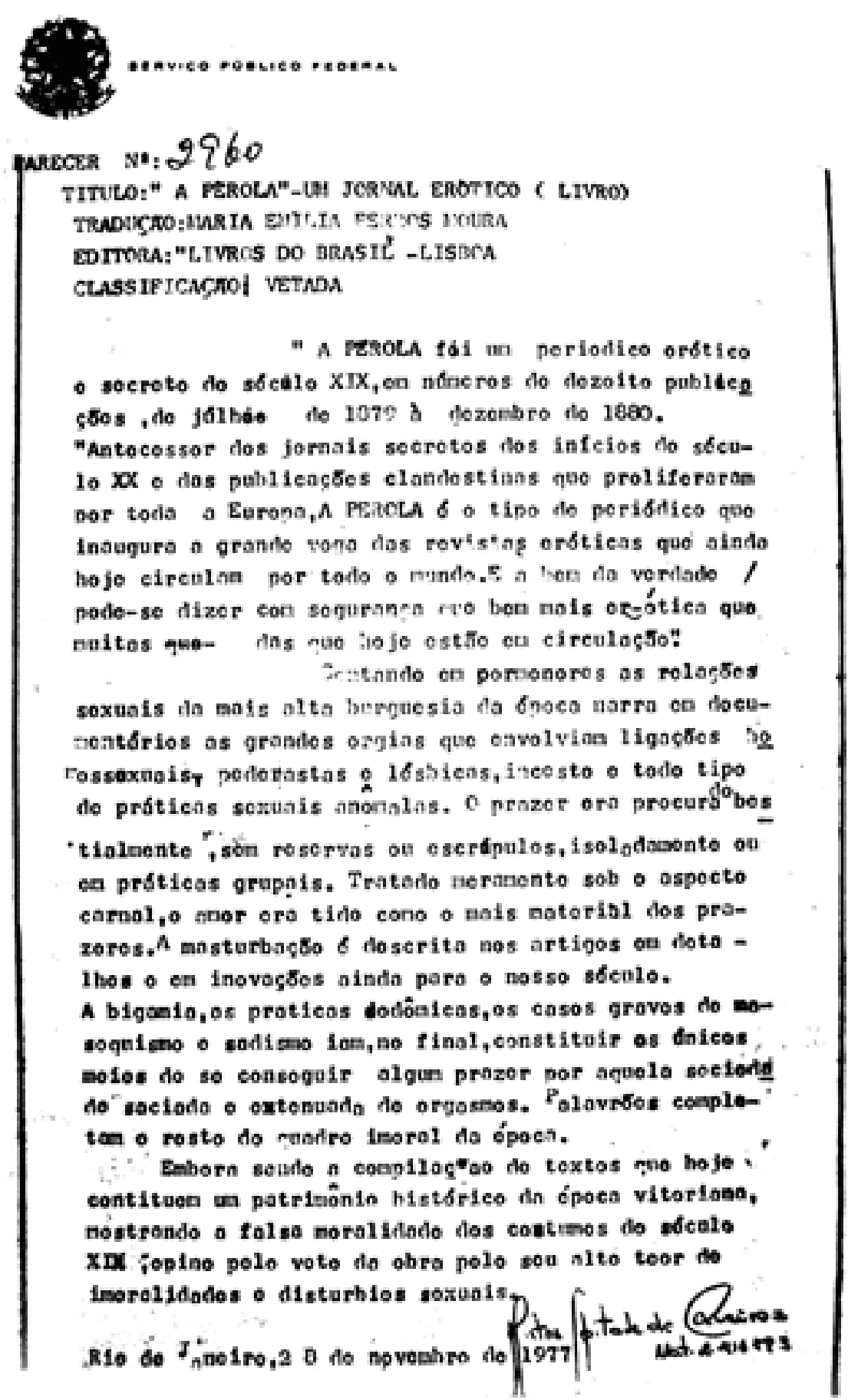

Lembremos que na consideranda do Decreto-lei 1077 está explicitado:

CONSIDERANDO que se tem generalizado a divulgação de livros que ofendem frontalmente a moral comum;

CONSIDERANDO que tais publicações e exteriorizações estimulam a licença, insinuam o amor livre e ameaçam destruir os valores morais da sociedade Brasileira;

CONSIDERANDO que o emprego desses meios de comunicação obedece a um plano subversivo, que põe em risco a segurança nacional.

No último parágrafo do parecer indicativo de veto ao livro A pérola - um jornal erótico, há uma ressalva importante: 0 parecerista afirma tratar-se de uma "compilação de textos que hoje constituem um patrimônio histórico da época vitoriana, mostrando a falsa moralidade dos costumes do século XIX", mas acrescenta que "embora sendo (...) patrimônio histórico (...), opino pelo veto pelo seu alto teor de imoralidade e de distúrbios
Fonte: cópia da autora

Quanto aos argumentos censórios e à dominância do artigo 1 do Decreto-lei 1077, destaquemos que o parecer de Aventuras de um sádico é o que mais explicita a vinculação com esse decreto: afirma vetar o livro em questão por "considerá-lo impróprio e agressivo", e que a publicação "outro destino não tem, senão, sexuais". Ou seja, do ponto de vista do censor, o valor cultural de uma obra não se sobrepõe a uma possível quebra da moralidade convencional.

Os pareceres censórios indicativos de veto acima citados datam de novembro de 1977, fase final do Governo Geisel (março de 1974 a março de 1979) quando já se começava a vislumbrar a possibilidade de alguma abertura política. Neste período, houve um crescimento proporcional da ação censória dos Serviços e da Divisão de Censura de Diversões 
Públicas, um crescimento que parece ter se dado, entre outros motivos, pelo fato "de que o próprio DCDP, percebendo a possibilidade do fim das atividades censórias, buscou mostrar-se como necessário ao sistema" (REIMÃO, p.26).

\section{Considerações finais}

Segundo uma conhecida afirmação que costuma ser atribuída ao escritor irlandês Oscar Wilde sobre livros e moral, "não existem livros morais ou imorais; os livros são bem ou mal escritos". Parecenos que os censores que elaboraram os cinco pareceres citados acima não concordariam com tal afirmação.

Há, por outro lado, entre os documentos censórios relativos a livros, um parecer, datado de 1977 e indicando a liberação do livro Kama Sutra, a sugestão de que deveria haver uma maior valorização, uma precedência da qualidade artística, literária ou cultural em relação a aspectos morais.

Imagem 4: cópia do exame do livro Kama Sutra pela Censura Federal

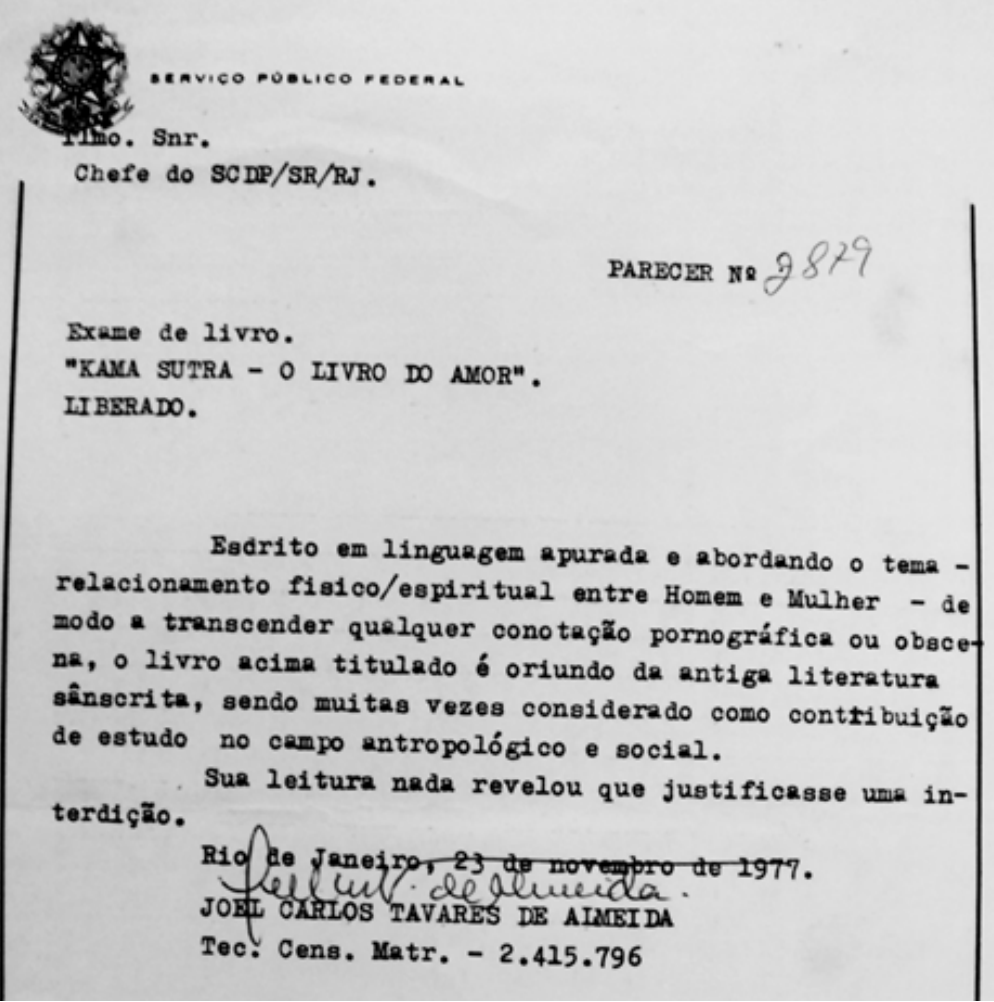

Fonte: cópia da autora
Exame de livro

KAMA SUTRA - O LIVRO DO AMOR

LIBERADO

Escrito em linguagem apurada e abordando o tema - relacionamento físico/espiritual entre Homem e Mulher - de modo a transcender qualquer conotação pornográfica ou obscena, o livro acima intitulado é oriundo da antiga literatura sânscrita, sendo muitas vezes considerado como contribuição de estudo no campo antropológico e social.

Sua leitura nada revelou que justificasse uma interdição.

Rio de Janeiro, 23 de novembro de 1977.

Pela data, vê-se que este parecer indicativo de liberação da obra Kama Sutra foi elaborado no mesmo mês que os outros cinco pareceres citados acima - todos de novembro de 1977 - provavelmente em função de uma mesma leva de importação de livros. É assinado pelo técnico de censura Joel Carlos Tavares de Almeida, cuja postura frente à cultura diverge da de seus colegas acima citados.

O livro Kama Sutra é mais uma vez alvo de exame censório em 1978, e o parecer, mais uma vez, indica a liberação. Este, datado de 23/02/78, destaca que o livro "é considerado o maior clássico da literatura sânscrita sobre a arte de amar. Seu autor, Vatsyayana, é um dos poetas eruditos da Índia”. Reforça que as "instruções eróticas da obra visam exaltar o amor, portanto não devem ser confundidas com pornografia" e que as ilustrações com órgãos genitais fazem "parte da arte indostânica". Por fim, o parecer conclui que: 
Pelo exposto e por ser obra conhecida universalmente, constituindo-se em fonte de pesquisa para os historiadores da civilização hindu, no campo sociológico e antropológico, opinamos pela sua liberação.

Os pareceres de liberação de Kama Sutra parecem não ter sido bem aceitos por parte da comunidade censória e, em 1979, o livro é mais uma vez examinado. O parecer datado de 22 de janeiro de 1979 afirma estar sendo elaborado devido a um pedido para que a Divisão de Censura e Diversões Públicas reexaminasse o caso: "Considerando 0 parecer liberatório, e atentando-se à ponderação: 'merecer um estudo mais apurado nesse órgão', o que consta o Ofício no. 11207/78-SCDP/SR/RJ, apreciou-se (...)".

O parecer de 1979 relativo à obra Kama Sutra indica, novamente, sua liberação. Destaca tratar-se "de obra antológica que retrata toda uma filosofia de vida". Mais do que isso, assinala que a obra foi editada em épocas anteriores, em sociedades bastante restritas do ponto de vista moral: "a obra foi editada pela primeira vez em Londres em 1873 e Paris em 1885, época esta em que a moral vigente se caracterizava pela dogmática inflexibilidade".

No sexto parágrafo, o parecer afirma: "Acima de tudo, dentro de seu gênero, a referida obra tratase (sic) de um clássico da literatura universal, contendo um marcante valor histórico, socioantropológico e cultural". Destacando esses valores, o texto argumenta que a "interditar-se tal obra cometer-se-ia uma obstrução, um obscurecer (sic) e uma negação de todos os valores acima citados".

Como último argumento a favor da manutenção da liberação do livro Kama Sutra, o parecer de 1979 indica que a interdição seria um caso de "retrocesso cultural" o que seria "inaceitável ao Órgão Censório e mais uma vez dar-se-íamos uma vergastada (sic) sobre a combalida imagem do Órgão". O parecer complementa que a interdição "seria por demais desgastante perante a Censura em si" e também "perante o Departamento de Polícia Federal e diante de todo contexto cultural vigente no país".
As discrepâncias de ideias e valores expressos em diferentes pareceres, e o fato de ter havido a solicitação de que um deles fosse refeito, atestam não haver homogeneidade na atuação dos censores, nem concordância entre as diversas instâncias dos organismos censórios. Entretanto, a não homogeneidade de atuação entre censores não ameniza o caráter negativo da repressão censória. A existência de legislação censória e de órgãos que possam impedir a circulação de produções culturais e artísticas representam, por si só, uma coação que restringe direitos e limita o exercício da cidadania.

\section{Referências}

BEJA, Rui Manoel Monteiro de Oliveira. A edição em Portugal (1970-2010). Percursos e perspectivas. Aveiro: Universidade de Aveiro, Departamento de Línguas e Culturas. 2011.

COUTINHO, Isabel, "Porto Editora compra Livros do Brasil e relança marca com Eça e Novo grafismo". Público (jornal), 8 jan. 2015. Disponível em: <https://www.publico.pt/2015/01/08/culturaipsilon/n oticia/porto-editora-compra-e-preparase-pararelancar-a-historica-livros-do-brasil-1681550> Acesso: 12.09.2017.

HALLEWELL, Laurence. O livro no Brasil. 2 ed. São Paulo: Edusp, 2005.

MEDEIROS, Nuno. "From Seashore to Seashore: The cross-Atlantic agenda of the publisher António de Sousa Pinto". Portuguese Studies. v. 31, n. 1, p. 84-93, 2015.

REIMÃO, Sandra. Repressão e resistência: censura a livros na ditadura militar brasileira. São Paulo: Edusp/ Fapesp, 2011.

SILVA, Deonísio da. Nos bastidores da censura. São Paulo: Liberdade, 1989.

SILVA, Flamarion Maués P. Livros que tomam partido: a edição política em Portugal, 1968-80. Tese (doutorado), Faculdade de Filosofia, Letras e Ciências Humanas, Universidade de São Paulo, 2011.

SOUZA-PINTO, António. "As relações culturais entre Portugal e o Brasil". Livros de Portugal - Boletim Bibliográfico n. 3, p. 9-10, jan. 1982.

Sítio eletrônico: <www.livrosdobrasil.pt>. Acesso: 12 set. 2017. 


\section{COMO CITAR ESSE ARTIGO}

REIMAO, Sandra. A editora portuguesa Livros do Brasil e suas obras eróticas na ditadura militar brasileira. Signo, Santa Cruz do Sul, v. 43, n. 76, mar. 2018. ISSN 1982-2014. Disponível em: <https://online.unisc.br/seer/index.php/signo/article/view/11086>. Acesso em:

doi: http://dx.doi.org/10.17058/signo.v43i76.11086. 